\title{
A GIS-based method of Lake Gucheng water quality assessment
}

\author{
Lizhi wang \\ Provincial Key Laboratory of Soil Conservation and Environmental Protection, Linyi University, \\ Shandong, Linyi 216000,China.wlzlyj@163.com
}

Keywords: GIS; TSI; Lake Gucheng.

\begin{abstract}
In order to study the water quality of Lake Gucheng, a geographical information system (GIS)-based method was used. The spatial distribution of eutrophication conditions in Lake Gucheng was investigated. A trophic stated index(TSI) consisting of four physical, chemical and biological indicators including total phosphorus (TP),total nitrogen(TN),secchi disk depth(SD),chlorophyll-a concentration(chl-a) was constructed to described the eutrophication state of the lake environment. A representation of the spatial distribution of TSITP, TSITN, TSISD, TSIChl-a was developed using the inverse distance weighted (IDW) interpolation method. Four thematic maps were synthesized a final map of the spatial distribution of eutrophication conditions. The results indicate that upper-mesotrophic conditions (TSI 50-60) cover most of the study area, while the eutrophic conditions (TSI 60-70) are distributed just in the northwestern part of the open water area .A very limited area in the central part of the study area is characterized as eutrophic (TSI 60-70). The high biomass of submerged mcarophytes contributed to the low TSI in the open water areas. human activities are responsible for the eutrophic conditions in the northwestern part of the Lake Gucheng.
\end{abstract}

\section{Introduction}

GIS technologies are currently undergoing a rapid expansion in the field of ecological surveying and modeling[1]. GIS represent a new approach to water quality assessment in the study of limnology. Since the 1960-70s, a number of attempts have been made to quantitatively evaluate the trophic state of lakes using single-variable trophic indices or multi-parameter approaches. However, these relatively simple single-variable trophic state criteria represent subjective judgments, and may be limited spatially. The multidimensional nature of the eutrophication phenomenon means that no single variable is representative of the eutrophication status of a given water body[2]. So a method for appropriate methodologies and tools capable of synthesizing spatially the eutrophication trends presented by various parameters is needed. By synthesizing such trends, a final thematic map illustrating the spatial distribution of eutrophication conditions can be created. Fortunately, this can be performed through use of a geographic information system (GIS).

The purpose of the present work is to integrate GIS techniques into the lake eutrophication assessment process of Lake Gucheng. The relationship between spatial distributions of lake eutrophication conditions and biomass of submerged macrophytes was analyzed also.

\section{Material and methods}

Study site and data collection. Lake Gucheng is located about $80 \mathrm{~km}$ from Nanjing and is a triangular shaped low altitude lake in SE China. The maximum length of Lake Gucheng is $10.40 \mathrm{Km}$, its maximum width is $8.20 \mathrm{Km}$ and it has an average depth of $1.56 \mathrm{~m}$. The catchment area is $464.50 \mathrm{Km} 2$. It is situated at an elevation of $5.5 \mathrm{~m}$, and $30^{\circ} 10^{\prime} \sim 31^{\circ} 26^{\prime} \mathrm{N}$ latitude, $118^{\circ} 44^{\prime} \sim 119^{\circ} 05^{\prime} \mathrm{E}$ longitude[3]. It is a water-passing lake with a long history of people living and agricultural development. The sources of water to the lake are surface runoff, atmospheric inputs and base flow. However, Lake Gucheng is mostly supplied by river discharge originating from the northeast mountain areas, and surface flow from the mountainous and hilly areas around the lake. In addition, the return flow water from the Yangtze River to the lake is also an important contributor during the Yangtze flooding. Lake Gucheng receives water inflow mainly from Xuxi River, Qiqiao River and 
Gangkou River, while Guanxi River is the only outflow river. The dominate species of Lake Gucheng are Potamogeton. crispus ,P.maackianus and Vallisneria natans.

Assessment indicators and their eutrophication scales. A trophic state index (TSI) on a scale from 0 to 100 was constructed[4]. The TSI was based on total phosphorus (TP), total nitrogen (TN), Secchi disk depth (SD), chlorophyll-a concentration (Chl-a) (Table 1). The 0-100 scale was divided into ranges, each representing a particular trophic state.

Calculation of eutrophication levels and generation of thematic maps. The following expression [4]was used to calculate the lake eutrophication levels for each of the indicators: TSI $i=(\mathrm{TSI} k-1+((C i-S i, k-1) /(S i, k-S i, k-1)) *(T S I k-T S I k-1))$

where $C i$ is the measured concentration of the $i$-th indicator ( $i=\mathrm{TP}, \mathrm{TN}, \mathrm{SD}, \mathrm{Chl}-\mathrm{a}), \mathrm{TSI}$ and TSI $k-1$ are the $k$-th and $(k-1)$-th scales of the $i$-th indicator, $S i, k$ and $S i, k-1$ are the evaluation standards of $k$-th and $(k-1)$-th scales of the $i$-th indicator.

The inverse distance weighted (IDW) interpolation methodwith a spatial resolution of $500 \times 500 \mathrm{~m}$ and ArcView Version 3.2 (ArcView 3.2, ESRI, Inc.) were used to generate the four thematic maps indicating the spatial distribution of eutrophication levels based on each indicator. The IDW interpolation method is based on the principle of assigning higher weights to data points closest to an unvisited point relative to those which are further away.

Table 1 The scale of the trophic state index (TSI) and the evaluation standards for Lake Gucheng

\begin{tabular}{cccccc}
\hline TSI & Eutrophication level & $\mathrm{TP}(\mathrm{mg} / \mathrm{l})$ & $\mathrm{TN}(\mathrm{mg} / \mathrm{l})$ & $\mathrm{SD}(\mathrm{m})$ & $\begin{array}{c}\text { Chl-a } \\
(\mathrm{mg} / \mathrm{m} 3)\end{array}$ \\
\hline 0 & Oligotrophic & 0.000 & 0.01 & 48.00 & 0.00 \\
10 & & 0.001 & 0.07 & 27.00 & 0.10 \\
20 & & 0.002 & 0.15 & 15.00 & 0.26 \\
30 & 0.005 & 0.30 & 8.00 & 0.66 \\
40 & Lower- & 0.010 & 0.60 & 4.40 & 1.60 \\
50 & mesotrophic & 0.023 & 1.00 & 2.40 & 4.10 \\
60 & Mesotrophic & 0.050 & 1.50 & 1.30 & 10.00 \\
70 & Upper- & 0.110 & 2.00 & 0.73 & 20.00 \\
80 & Eutrophic & 0.250 & 3.00 & 0.4 & 40.00 \\
90 & Hypereutrophic & 0.550 & 4.60 & 0.22 & 100.00 \\
100 & Extremely & 1.200 & 10.00 & 0.12 & 200.00 \\
\hline
\end{tabular}

The overlay of the thematic maps.The overlay technique, widely used in GIS applications[5, 6], was applied to synthesize the four thematic maps and develop the final eutrophication map(Fig.1). The following steps describe the synthesizing procedure used to analyze the six thematic maps:

1. Development of a trophic state index (TSI) scale from 0 to 100 to label the different trophic levels.

2. Application of this ordinal scale to all the pixels/cells on each thematic map; each pixel was assigned a value from 0 to 100 based on a comparison between its initial value and the eutrophication scales.

3. Analysis of the four thematic maps on a cell-bycell basis. As a result, a final map illustrating the spatial distribution of eutrophication levels was produced. The following expression was used in the overlay operation to produce the TSI values:

TSI $=($ TSIT $*$ PWTP+TSIT*NWTN+ TSIS $*$ DWSD+TSIC*hl-aWChl-a)

where TSITP, TSITN, TSISD, TSIChl-a are the eutrophication levels for TP, TN, SD, Chl-a on the four thematiclayers; WTP, WTN, WSD, WChl-a are the weighting factors for each indicator (assumed as $1 / 4$ for each indicator in the operation). 


\section{Results}

The thematic maps of TSITP, TSITN, TSISD and TSIChl-a developed using the IDW interpolation method and the eutrophication scales, are illustrated in Fig. 2, respectively. Fig. 2 shows the spatial distribution of TSITP. The northern part of Lake Gucheng is characterized mainly as severely eutrophic (TSITP 70-80), while the eutrophic field (TSITP 60-70) is distributed in the eastern part of the lake. From the distribution of $\mathrm{TSI}_{\mathrm{TN}}$, most of the studied area can be characterized as upper-mesotrophic $\left(\mathrm{TSI}_{\mathrm{TN}}\right.$ 40-50). The distribution of $\mathrm{TSI}_{\mathrm{SD}}$ shows the northern part of Lake Gucheng is characterized mainly as upper-mesotrophic(TSI SD $^{50-60)}$. while the mesotrophic (TSISD 50)conditions can be observed in the open water areas. The distribution of $\mathrm{TSI}_{\text {chl-a }}$ shows in the open water areas of Lake Gucheng is characterized mainly as upper-mesotrophic(TSI chl-a $_{\text {-a }}$ 50-60).

Finally, the overall TSI spatial distribution shows upper-mesotrophic conditions (TSI 50-60) cover most of the study area, while the eutrophic conditions (TSI 60-70) are distributed just in the northwestern part of the open water area .A very limited area in the central part of the study area is characterized as eutrophic (TSI 60-70)

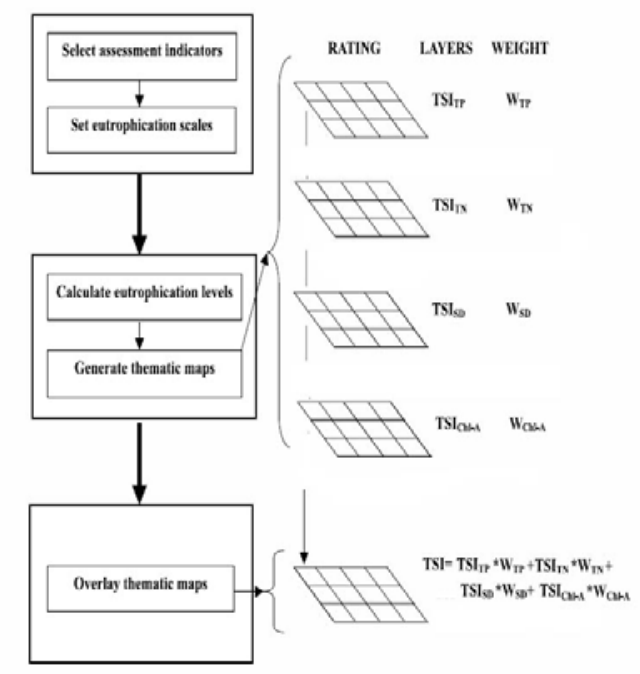

Fig. 1 The flow chart for the GIS-based method for lake eutrophication assessment.

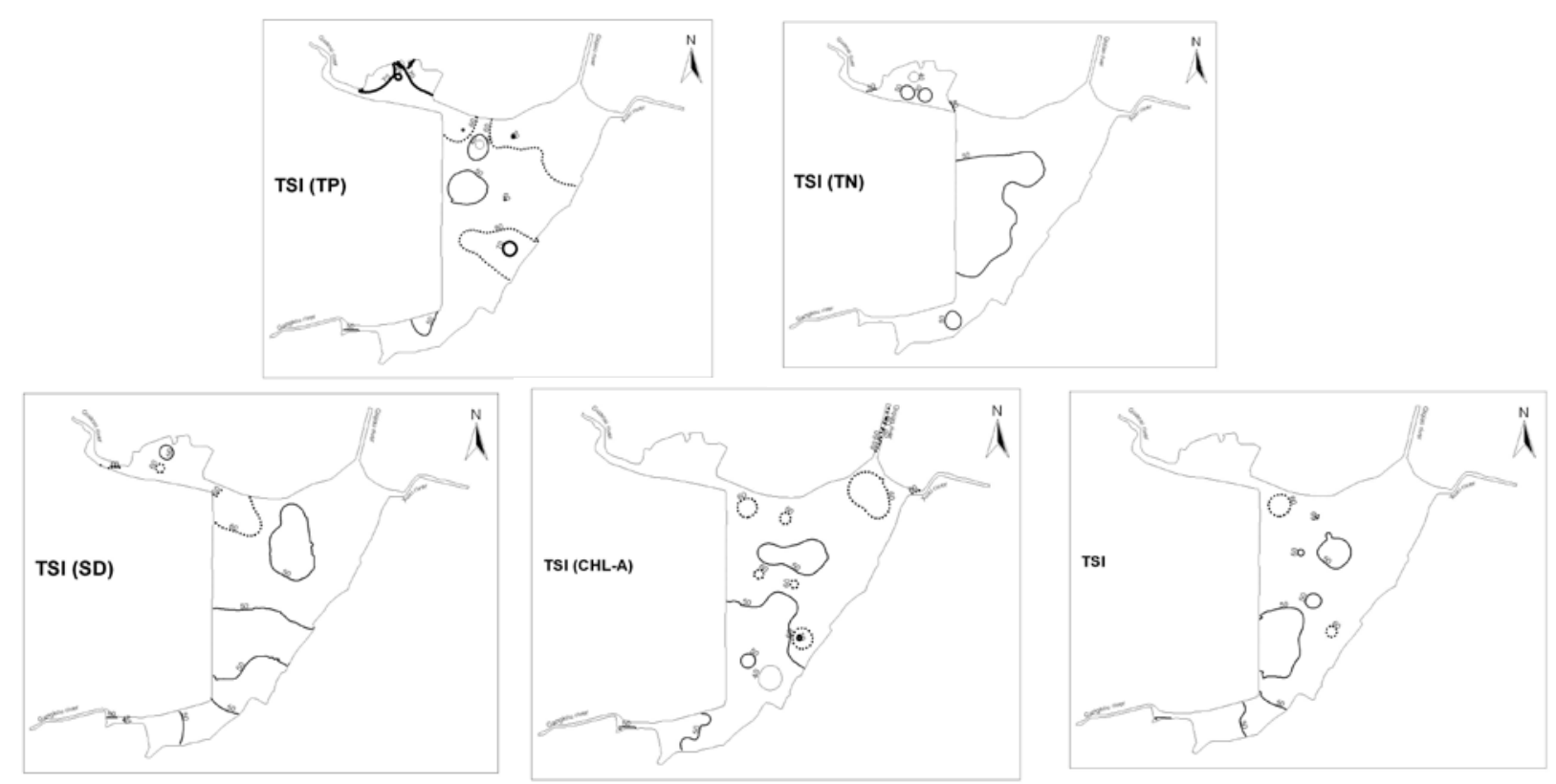

Fig. 2 Spatial distribution of the lake trophic state index based on each indicatorDiscussion 
The spatial distribution of Lake Gucheng's eutrophication levels derived from this study is closely correlated with the actual conditions of the lake. The northwestern part of the lake, especially the river mouth near the Guanxi River, receives much more wastewater because of their nearness to Gucheng City. The nutrient contents which are primarily responsible for eutrophication in this area.

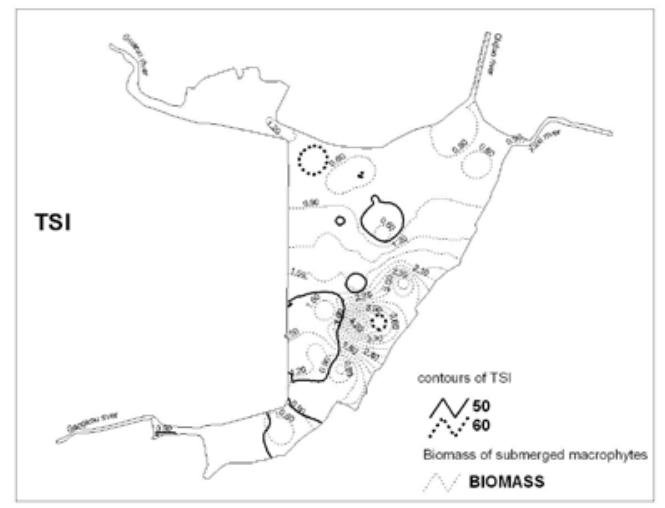

Fig. 3 Spatial distribution of the lake trophic state index and biomass of submerged macrophytes(biomass of submerged macrophytes $\mathrm{kg} / \mathrm{m}^{2}$ )

The biomass is high (Fig.3) in the open water areas. The overall TSI is 50-60 in the open water areas. So the low TSI maybe explained by the high biomass of submerged mcarophytes. Submerged macrophytes can maintain clear water state of macrophyte dominance by various buffering mechanisms such as fast growing, bicarbonate utilization, luxuriant uptake of nutrients and allelopathy[7]. They provide refugia for the largebodied cladocera, which are highly efficient harvesters of phytoplankton. The macrophyte-dominated ecosystem is usually structured with high biodiversity. The removal of nutrients by biomass harvesting and the moderate utilization of submerged macrophytes by cage culture of herbivorous fishes maybe another for the low TSI in open water areas.

\section{Acknowledgment}

The authors thank the National Natural Science Foundation of China (41303061), the Open Foundation of Shandong Provincial Key Laboratory of Water and Soil Conservation and Environmental Protection (stkf201206), the Research Fund for the Doctoral Program of Linyi University (LYDX2013BS063). The research fund for excellent young and middle-aged scientists of the Shandong Province (BS2014HZ013), the Natural Science Foundation of Shandong Province of China (ZR2013CM002) and the Science and Technology Development Funds of Linyi City (201412025) provided support for this research.

\section{References}

[1] D.C. Williams and J.G. Lyon, Historical aerial photographs and a geographic information system (GIS) to determine effects of long-term water level fluctuations on wetlands along the St. Marys River, Michigan, USA. Aquat. Bot.58(1997)363-378.

[2] F.L. Xu, S. Tao, R.W. Dawson, and B.G. Li, A GIS-based method of lake eutrophication assessment. Ecol. Model.144(2001)231-244.

[3] Z. Huang, B. Xue, and Y. Pang, Simulation on stream flow and nutrient loadings in Gucheng Lake, Low Yangtze River Basin, based on SWAT model. Quatern. Int.208(2009)109-115.

[4] R.E. Carlson, A trophic state index for lakes. limnol.22(1977)361-369.

[5] S.B. DeVogel, J.W. Magee, W.F. Manley, and G.H. Miller, A GIS-based reconstruction of late Quaternary paleohydrology: Lake Eyre, arid central Australia. Palaeogeogr Palaeoecl.204(2004)1-13. 
[6] J.L. Ehman, W. Fan, J.C. Randolph, J. Southworth, and N.T. Welch, An integrated GIS and modeling approach for assessing the transient response of forests of the southern Great Lakes region to a doubled $\mathrm{CO}_{2}$ climate. Forest Ecol.Manag.155(2002)237-255.

[7] J. Gao, Z. Xiong, J. Zhang, W. Zhang, and F. Obono Mba, Phosphorus removal from water of eutrophic Lake Donghu by five submerged macrophytes. Desalination.242(2009)193-204. 